\title{
Reflexivity in Leadership Coaching at a B-school in India
}

\author{
Manab Bose \\ HR \& OB Area, Indian Institute of Management Udaipur, Udaipur, India
}

\section{Email address:}

manab.bose@iimu.ac.in

\section{To cite this article:}

Manab Bose. Reflexivity in Leadership Coaching at a B-school in India. Education Journal. Vol. 10, No. 4, 2021, pp. $147-153$. doi: $10.11648 /$ j.edu. 20211004.15

Received: June 27, 2021; Accepted: July 19, 2021; Published: July 29, 2021

\begin{abstract}
The paper argues that India is no more just a jugaroo nation because of its growth trajectory among the lower middle-income economies. Innovation in India has begun to track above the average of the upper middle-income nations in all innovation indicators. India's demographic profile of a young population needs to take advantage of this growth by using all the opportunities that the $21^{\text {st }}$. century has to offer. One such innovation in education is what the paper demonstrates as a doable model of leadership coaching. The author takes into account the significance of conventional leadership coaching and blends it with contemporary psychodynamic theory and organization-development practice. If one purpose of leader coaching is to build personalities beyond normal limitations, then education and training will have to provide non-threatening methods by which embedded dynamics in the inner theater of human personality can be explored. The case-study provides evidence of this education and exploration, drawing on Kolb's experiential learning model, and offers an advanced leadership training course which unfolds over four modules, in an eight-year experience at a premier b-school in India. Young women and men in the final year of the MBA course become mindful and sensitive of their own influences and assumptions, and develop the ability to connect the internal psychodynamic world with societal and global processes that influence transferences and counter-transferences for effective decision-making as they get ready to take up leadership positions in various organizations. Business-case reviews about the decline and demise of enterprise bring home the dysfunctionalities of toxicity in individuals which, remaining unresolved, spreads to groups and organizations. Film-based discussions on neuro-psychology and neuroelasticity demonstrate how the human brain messages changed responses to situations of toxicity-induced threats by releasing new and proactive leadership behaviors. Even if $10 \%$ of a Class carry forward the learning from this innovative paradigm of leadership coaching into day-to-day decision making, the original idea of young men and women who are aware of their own influences and assumptions in leadership positions will begin to snowball.
\end{abstract}

Keywords: Coaching, Action Learning, Leadership, Management Education, Psycho-dynamics

\section{Introduction}

India has been labeled a jugaroo nation by partisan academics in the West, because India is a reliable vendor for application of products owned by international firms. Jugaad is a colloquial word, which refers to a non-conventional, frugal innovation. It could also refer to an innovative fix or a simple work-around, a solution that bends the rules. It is also often used to signify creativity: to make existing things work, or to create new things with minimum resources. Jugaad is increasingly accepted as a management technique. [1]

Jugaad is also gaining recognition as an acceptable form of frugal engineering. [2]

According to Jaideep Prabhu, academic at Judge Business
School, UK jugaad is an important way out of the current economic crisis in developed economies and also holds important lessons for emerging economies [3].

The Global Innovation Index 2020 report ranked India $48^{\text {th }}$. and entering the top 50 nations for the first time. India, Kenya, the Republic of Moldova, and Viet Nam hold the record of being innovation achievers for 10 consecutive years. India ranks $3 r d$ among the economies in the lower middle-income group and has an overall innovation performance that is above the average of the upper middleincome group in all innovation dimensions. [4]

Shashi Tharoor, ex-UN diplomat and Member of Parliament in India, made a pitch for policies to provide right kind of education, including skill development and vocational training, to youngsters to address the issue. Sixty five per cent 
of our population is under the age of 35. The ILO (International Labour Organisation) says in 2030 we will have 160 million people on the job (with the) starting age group of 19 to 23, whereas China will have only 92 million. So, we are going to be, in a sense, in a position to be the dynamic, productive, youthful nation. He made the remarks at The Economist Summit 2018 held in Mumbai. But all of this will make sense, will only be a demographic dividend if we can in fact equip these young people to be able to take advantage of the opportunities the $21^{\text {st }}$. century offers," he added. [5]

If education is to become the vehicle of transformation, India will need leaders who are in touch with their inner theater. Manfred Kets de Vries explains the inner theater relates to questions like: What are the things that motivate you? What are the things that are important to you? What are you deeply passionate about? How do you feel about certain things? How well do you understand how you affect other people? All these things have to do with a person's inner theater... If you don't know what you are doing, it is really hard to be effective in many ways. If you want to be an effective leader, it is important that you have a sense of what you are all about; what you do well, and are not so good at. If you are not good at certain things, maybe there is something you can do about it... [6].

Management guru Peter Drucker immortalized this: Leadership is not magnetic personality, that can just as well be a glib tongue. It is not 'making friends and influencing people', that is flattery. Leadership is lifting a person's vision to high sights, the raising of a person's performance to a higher standard, the building of a personality beyond its normal limitations. [7]

\section{Method}

The course unfolds over four (4) parts.

\subsection{PART A Is Reflective, from the Self}

This inaugural part brings reflective focus on events from childhood. Pulin Garg, iconic late-Professor at IIM Ahmedabad in the 80s and 90s, and pioneer of I-Group explorations, explains in a paper To understand individual and organisation behaviour an awareness of symbolic identities and psychological role models available through socialisation in the Indian family is very necessary. Their roots lie in the traditional ethos of the agrarian society. They are deeply embedded in the individual. They define his modes of relating to individuals and systems. The symbolic identities and psychological role models of the western technological society are available in knowledge. They are often idealised. Systems and structures, rules and regulations are introduced to promote their operation in Indian organisation. But they are largely cognitive. They are not rooted in the emotive and action structure of the individual. [8]

Current psychoanalytic organisation theory is a psychodynamic framework assembled around the idea of identity. The concept of identity transcends self while at the same time defines self in a relational and intersubjective context. It assumes that at the human core of organisations is a collective sense of self activating itself in a context. Individual introjections and projections shape how an individual identifies and aligns with the objectives of a group or organisation. This collective identity influences students' perceptions and narratives of organization work and life.

The first draft of Personal History is a requisite for the first one-on-one meeting between the student and the Leadership Coach. The Leadership Coach also facilitates classroom discussion of two self-administered psychometric tests, one on Conflict Management and the other on Leadership Traits, which the students decode and capture the data in the personal history document. The second one-on-one meeting moves to psychoanalytic interventions. Before this meeting, each student, with the aid of a set of guidelines, interviews at least one parent and adds the findings to the personal history, thereby capturing the projections and transferences from infancy that have shaped identity formation. Freud wrote about the significance of surfacing personal histories, by reminding us that all the essentials lie beneath the surface of mind, buried and inaccessible. Analytic interrogation into ancestral roots, of both the individual and the human species.

The Leadership Coach facilitates identification of dysfunctionalities in the self that block exploration of new leadership behaviors. The focus of innovation in this pedagogy is the self, as experienced by the student in three domains: personal motivation, personal feelings / attitudes, and personal attributes. [9]

Using this new knowledge about the self, the student drafts a personal SWOT and an Action Plan. For management students, a tangible blueprint for action is helpful.

The one-on-one sessions facilitate the identification of strengths along with the layers of toxicity accumulated below-the-surface. This repressed material undergoes resolution, leading to gradual acknowledgment that experimentation and exploration of new, proactive behaviors is possible. The Class becomes familiar with the phrase below-the-surface, as opposed to use of the psychoanalytic personal unconscious which raises eyebrows at b-schools and industry in India.

When you own this story, you get to write the ending. [10]

\subsection{PART B Is About Learning from a Leader, in Real-time}

It is recognized globally that to bring about transformation in organizations, exercise of leadership with sustained efforts is necessary. In this context, the second part of the program is dedicated towards a dialogue with leaders in India who have influenced and acted to bring about transformation in their organizations. Discourse with real-life leaders help conceptualize the challenges of leadership behaviors such as risk-taking, thinking out-of-the-box, innovating, listening \& inspiring, influencing other team-members, meeting tight time-schedules as well as factors that are relevant in the context of India. These intimate dialogues help build key takeaways for personal reflection. The small team of students embark on the study of the individual leader assigned, and 
prepare first, a psycho-social history from available data both in the public domain as well as through confidential 360 feedback and ESat processes. They then design two questionnaires, of increasing intensity, with the objective of unravelling deeper truths faced by the leader.

The first questionnaire is based on two pieces of research that is made available to the Class. The first study highlights the following specific differences between Indian and Western leaders. For Indian leaders:

1) Leadership is not about cleverness at strategy or even because of the efforts of a top team.

2) No mention of skill in financial markets, mergers and acquisitions, or deal-making talents that Western CEOs often claim underpin their companies' performance.

3) Almost without exception, the leaders said their source of competitive advantage lay deep inside their companies, in their people.

4) Far more than their Western counterparts, the leaders and their organizations emphasized a long-term, internally focused view.

5) They spoke about creating a sense of social mission that is served when the business succeeds. Shareholder value is \# 4, compared to \# 1 for Western leaders.

6) They highlighted the need for aggressive investments in employee development, despite tight labor markets and widespread job-hopping. And they strive for a high level of employee engagement and openness. [11]

The second study is the latest Globe 2020 Report, published in October 2020. The feedback on India shows the cultural practices and values of Indian leaders along with the leadership scores of outstanding leaders. [12]

Leaders of the most successful Indian companies engage with the nation, the culture, and employees in that order, and this is an important factor in their performance This is the inclusiveness of Indian ethos, without sacrificing organization task.

One of the aspects of Indian-ness explained by Sudhir Kakar, an Indian psychoanalyst, is the subsuming of individual identity in group interests. A Westerner, he says, is more likely to say 'I want to achieve this' whereas in India individual achievement gets tied up with family pride or, at a wider level, with community. [13]

Each team crafts the psycho-social profile of the leader assigned, and develops the first questionnaire for engaging the leader.

The second set of Qs digs deeper into the personality and psychological characteristics of the leader.

This dialogue helps students to understand how the Indian business leader performs both charismatic and instrumental roles, and unravel the mechanisms by which leadership exerts influence in organizations.

Although students work in small teams, it is mandatory for each student to analyze personal learning from discussions with the leader, and add this to the Action Plan for review with the Leadership Coach during the one-on-one.

\subsection{PART C Is About Experiential Learning}

Gouranga Chattopadhyay, pioneer of Group Relations in
India and ex-Professor of IIM Calcutta, says that The principal task of a manager is to provide and maintain boundaries, primarily of task, time and territories, and secondarily of many other resources, in such a way that those within the boundaries, including the managers themselves, can engage with the tasks of the system with least difficulty. Since every person manages some systemic tasks and relations, the concepts dealt with in this article are very real in most person's life. In order to manage systems and their boundaries, each person has to primarily manage oneself in one's various roles. [14]

This part of the course provides experiential learning, and training the mind in real time, to engage with the primary task of the organization / group without distraction. This is a crucial aspect of leadership development. Can we train ourselves to respect personal preoccupations, thoughts, feelings and hold them in Bion's container and containment so that these do not interfere with the primary task? [15] The Indian ethos of inclusiveness makes us want to engage with personal preoccupations, thoughts, feelings while simultaneously engaging with the primary task of the group / organization.

The Class is immersed in a sequence of events where each student gets the opportunity, in real-time, to experience the personal preoccupations, thoughts, feelings that tend to become dysfunctional in the context of the primary task decided by the group. Consequently, students also get to test the new leadership behaviors that are captured in the Action Plan. The design of this reflective intervention also offers opportunities to:

$\# 1$ : test in real-time previously untested fears, anxieties, and assumptions that tend to generate toxicity in both the self and the organization. Consequently, use personal authority for leadership behavior, keeping in mind all consequences,

\#2: develop comfort in own strengths as they play out in the context of a group setting, resembling organizations, and

\#3: modify and adopt the new behaviors into the Personal Identity as it keeps evolving.

This is an innovation within the international Group Relations model of experiential learning, drawing on the dual traditions of two flagship programs of Sukrut - the annual Inward Change Conference and the annual The India Conference (www.sukrutindia.in). The international root rests in the annual Leicester Conference of Tavistock Institute, UK (www.tavinstitute.org). Both systems offer an unique arena for live investigation of the processes that occur in organizational life, and the opportunity to examine, in the here-and-now, what can promote and what can obstruct proactive action, change and development. The structure of this part is activated in a 04-day back-to-back, residential setting. The Class is facilitated to explore and test hypotheses about what actually happens within and between groups, in multiple exercises bounded by the time, the task, and the territory in which meetings take place. This sensitizes students to experience the powerful and conflicting human desires between being part of a group and wanting to fit in, and the need to demonstrate uniqueness and individuality. A 
key thrust of the GR event is to develop awareness of the toxicity within oneself that generates reactivity from others on the spot. Prompted by the Leadership Coach and his team of trained Facilitators, the student resolves to let go the dysfunctionality, and releases proactive action to address the challenges faced by the group. [16]

\subsection{PART D Is About Closure}

This part provides opportunity to students to seek clarifications while they receive some concluding inputs. The Leadership Coach uses a case and film-clips to nail any doubts that may still linger about toxicity in individuals that lead to dysfunctional behaviors. Plus, there are a few filmbased sessions on neuro-psychology and how the brain activates responses to situations of threat by messaging the release of new leadership behaviors. [17]

Finally, the last one-on-one is when the student stitches all the learnings in a final two-year Action Plan document.

\section{Result}

The course draws on Kolb's experiential learning model, where learning occurs through a four-phase cycle that includes:

1) experiencing (concrete experience),

2) reflecting (reflective observation),

3) conceptualizing (abstract conceptualization), and

4) applying (active experimentation).

The model suggests that learning is incomplete or less effective without all four phases. [18]

Standing on Kolb's conceptual stool, not necessarily in the above-mentioned order, the course is about:

1) Reflections about the self through Personal History writing, towards Identity Formation,

2) Learning from real-life leaders, in real-time,

3) Classroom discussion on Psychodynamic Theory and Neuropsychology, using case and film-clips, and finally.

4) Freudian talking cure, one-on-one, to identify toxicity and dysfunctional behaviors in the self, followed by immersion in a Group Relations event to test new leadership behaviors.

It's fair, perhaps, to say that psychotherapists have more intensive training in personality dynamics, while executive coaches focus more on the general work environment in which executives operate. But it's my conviction that therapists can benefit from knowing more about the organizational world, and coaches without training in psychology would do well to acquire its basics. In my own work, I often move from past to present and from conscious to unconscious material. Both as a therapist and as a coach, I've had some assignments that were short and highly focused and others that lasted for years. [19]

Needless to emphasize, the Leadership Coach (or Faculty) is important for a course of this intensity and must meet the above requirements.

\section{Discussion}

The following quotes from alumni illustrate the four recurring themes essential for learning about leadership through reflexivity:

1) explore the (unconscious) dynamics of events and problems, beginning with personal fears, anxieties, and assumptions that keep alive dysfunctional behavior and repressed toxicity,

2) make sense of ambiguous personal experiences,

3) better relate to others by integrating multiple, contextualized perspectives, and

4) develop and maintain ethical and responsive management.

There is evidence that the course has benefitted individuals. The quotes:

1) ALC helped me a lot to change my outlook and behavioural aspects. I understood that there is a huge difference between a Manager and a Leader. Leadership is a skill which you have to develop and practice in day to day life. Moreover, somehow I feel it also gave me the strength to manage my emotions and provided mental peace. I still remember the lectures where we were nudged to figure out the unknown territories and out of box ideas, and right now in my corporate life I am finding the huge necessity for everyone whether it's an employee or the organization, to work on the same lines. On personal front, the course has really helped me to set priorities in life. Overall course structure helped create a preface for corporate life as a leader and social life as a peaceful soul.- PB (2013).

2) In an MBA curriculum, where there are many courses to help one understand the business, understanding oneself personally during that tenure is inevitably critical. During $M B A$ or even before that, we were so running to meet deadlines, grasp concepts and acquire all kinds of hecessary" skills to be better managers, that we forget to spend time on ourselves, which is of utmost importance. It is a prerequisite that a manager needs to know himself/herself exhaustively. This course helped me in exploring myself as an individual. Post MBA, we are overwhelmed with major decision-making both professionally and personally. ALC not only helped me in my thought process by showing the broader picture and not missing the long term scenario while taking decisions, but it also enabled me to plan my career considering all the different angles in the process. It's an art to take everyone along to reach to a conclusion and I started learning that art with ALC. The art has helped me with the skill of conflict management both at my workplace and home. A leader needs to be balanced as a person, and I am thankful to ALC for instilling this important ingredient in me. - NJ (2017).

3) Dear Professor, please find my presentation on the PLJ in the attachment to this email and let me know if any other document needs to be submitted! Regarding my experience in the course, I would like to say that it was surprising journey for me in the sense that I was not expecting to discover so much about myself in such a short time. During my studies and work life I was constantly encouraged to look outside 
and evaluate everything around me but myself: customers, competition, revenues, macroeconomic situation etc. And it seems that there was neither place nor time for looking inside and asking such simple yet important questions as ,Who am I? ", ,Why do I act as I act?" and "What are my fears of being a leader? ". During the workshop I finally had time and courage to ask these questions and think about possible answers. It was not an easy path to walk: I was constantly challenged by you, your colleagues and the whole members' group, and from time to time I felt exhausted. Despite (and maybe because of) that, I gained a lot of new thoughts and inspirations in our GRC sessions, 1-on-1s and interview with my assigned leader at the beginning of the course and would definitely recommend it to the future students! Again, I would like to thank you for this course, your patience and support. I am very happy that I took this course and will also inform my university about this new experience. Who knows, maybe it could benefit future students in Germany as well! - Thu, Dec 6, 2018 at 5:09 PM.

To: Me

From: AS, an exchange student from Germany, in 2017

4) Greetings Sir, I hope you are doing well. I am currently based out of NCR, with my family, and have started my corporate journey. When I talk about the journey, as I had already mentioned, my MBA would not have been complete without this course. And I stand by it. It was actually the right time for me to have a self reflection and face the difficult things which I had been ducking all my life. And the takeaway for me had been the 'understanding of Primary Purpose'. I remember the very exact moments when you had mentioned the concept to me and this concept has been something which I have looked upon since the course came to a conclusion. I have had pretty bad time ever since this year started, and there came a dark phase wherein I was too much into thinking dark things. Poor thoughts had taken birth in my mind. Primary Purpose was somewhere a reason which brought me out of them. And I am glad that I had those conversations with you and Uday Sir which brought in this understanding and made me look at a clearer picture. Thank you so much Sir for everything. Thanks \& Regards.

AS, Class of 2019-21 to me 12:08AM on 11 May 21

Business Impact

There are several examples of a new leadership paradigm emerging out of interventions emerging from reflection.

Students of earlier Classes, now in some years of employment in Indian and multinational companies, have been reporting minor successes in their endeavor to integrate the learning from this course.

Case \# 1: A student from the Class of 2013 experimented with an issue that was showing early signs of toxic build-up. This was at an institution where he was registered for Doctoral studies, in 2015. A satisfaction-survey with finalyear students showed dissatisfaction with the dining facility in the institute; this service was managed by the Administrative Head and the Warden of the hostels who between them decided the menu, selected the vendor, and fixed the annual cost per student which was the INR equivalent of Euro 5000. Dysfunctional attitudes and behavior was about the number of dishes in the menu, the quality, and the commensurate cost. This student, representing the Dining Committee of the college, met the Director and proposed a solution: if consumers of the oncampus dining facility were predominantly students, they need to be permitted to decide the menu and the cost, select the vendor, and oversee quality. The argument that a matter which affected adults directly and personally was debated at the Faculty Council who took the decision that the Dining Committee of students would manage the service. The College Administration would continue to manage the accounts. Menus were redesigned with the help of a nutritionist, a new vendor was selected, and the annual cost went down to Euro 4250.

Case \# 2: Delays in the home-delivery of a second standby cooking-gas bottle in a new $10 \mathrm{Kg}$ cylinder was leading to loss in market-share for the company that employed this student from the 2014 batch. He interviewed $75 \%$ of the consumers in his region, and decoded their feedback to understand that although they were happy with the after-sales service of the company, they have resisted paying for and storing an additional stand-by bottle. On the other hand, if the company could supply a smaller, manageable stand-by bottle, they would be happy. Consumers also gave feedback about the distributors, which helped him to decode the operational bottlenecks of supply because of the accumulated toxicity in the vendor community. This study was extended all-India, and the report supported that from this region.

The student conceptualized a $5 \mathrm{Kg}$ bottle that was cheaper and easily manageable by way of transport and storage. He also built a business plan to manufacture and sell, and the company agreed to test-market. A distributor began supplies to consumers in his region from mid-2016, and the company soon regained the lost market share. With this success in a few other regions, the company planned a pan-India rollout of a $5 \mathrm{Kg}$ cylinder from mid-2017, reaping huge revenues from an innovative product line. The company also had enough all-India data to mitigate distributor / vendor toxicity. Listening to the marketplace and decoding data from belowthe-surface gave this ex-student a boost in his career in 2019.

Case \# 3: An ex-student from the 2015 batch reported this experience with her employer, a full-service commercial airline in India which is just about three years old. Analyzing the profiles of Business and Premium Economy travelers, who were also loyalty members and mostly seniormanagement executives in decision-making roles, she prepared a short-list of 100 individuals from the major metros to meet them personally. In these meetings spread over three months in 2016, she discovered and decoded two pieces of data that lay below the surface: the prestige and status of using a new airline with new frills had worn out and, second, there was nothing that pampered the need for "exclusivity" in this band of senior commercial executives. Status and power rarely manifest in public settings such as an airport or in-flight; what she heard these consumers say is "we pay more than others and deserve more than others, not 
just in-flight but on the ground too". Beyond the standard practice of airline lounges for loyal customers, she began to conceptualize services that would enhance the psychological need for "exclusivity" and "centrality" that these vacuous customers expected. But new features would cost money, and would not get past her cost-conscious bosses. Her business plan included a marginally higher fare in Business Class only, in order to offset the additional cost of a personal attendant / chaperone / valet that she proposed. Post launch of this service in January 2018, feedback from this segment of fliers indicated higher satisfaction levels, as well as committed business to the airline from their companies.

Case \# 4: An ex-student from the Class of 2017 reported the installation of a formal engagement mantra for clerical employees, in the form of an anonymous electronic feedback system where employees could post grievances and get a response within seven days from management. This appeared difficult in a public-sector bank, but he implemented it and the system became popular in a year. Analyzing the collated data, the student was able to decode a case of organization psychodynamics embedded in toxic policies and practices, leading to high levels of employee dissatisfaction and disengagement, absenteeism, and pilferage of company property. An old company policy permitted submission of OTC medicine bills up to Euro 10, reimbursed of which would take up to six months. For the biggest bank in India, this was a lot of legitimate liquidity of employees lying blocked, leading to simmering anger against managementcentered policies. Management answer was that it took time to scrutinize each bill, because there were so many every week. Moreover, as a PSU bank, the company was subject to Government of India audit, and every bill had to pass the authenticity test. The ex-student picked up and decoded all these "below-the-surface" information in casual chats with clerical employees in the cafeteria, where "management" was described as "heartless". Probing further, he came to know of many such practices that had become toxic, but one tangible practice that he could address was this matter of reimbursement. He began to surface the issue with senior colleagues and, finally, encouraged by them he prepared a recommendation that medicine bills up to Euro 10 need not be scrutinized because the bank incurred almost double the expense to process per bill, in employee cost and overtime. Based on his policy note, Management passed a Board resolution that an OTC bill up to Euro 15 would not be checked, and reimbursed within seven days.

These companies became curious about entry-level talent demonstrating initiatives in personal authority impacting company policy, and want to hire more such graduates.

\section{Conclusion}

Leadership education and training in b-schools can bring about a paradigm shift in the personality development of future executives, by making them aware that below-thesurface processes exist in all collective human endeavor, in an organization as much as it exists in an individual. They can then get training through reflective courses to learn to listen to customers, vendors, employees and then use the skill of decoding the feedback, decipher the toxic elements that need redressal. Needless to add, case-discussions and filmreviews under a psycho-dynamic lens supports the reflections in this blend of traditional leadership training and psychodynamic theories.

Students signing up for this course are familiar with the standard, cognitive concepts of leadership. A list of textbooks and articles are given as the course progresses, indicative of the advanced and psycho-dynamic nature of the program. It is important for students to reference-read and view films that help bridge the gap between a cognitive appreciation of leadership concepts and the real, at times toxic, impact of accumulated feelings in decision-making, at the level of self and its interface with the system.

The books, papers and films that were prescribed in 2020 are:

1) Rebel Ideas, by Mathew Syed.

2) Understanding Organizations, by Charles Handy.

3) Notes on Managing Conflict, by Thomas Kilmann.

4) Notes on The Achievement Motive, by David McClelland.

5) "On Leadership: An Interview with Manfred Kets de Vries".

6) Papers and films on Feelings, Organization Psychodynamics, Neuropsychology.

The course is part of the curriculum. Consequently, it's assessment formula is:

Class Participation - 10\%

Learning from Leader - $20 \%$

Learning from GR event $-50 \%$

Practicality of Action Plan - 20\%

Individual toxicity contaminates organizations commercial \& industrial, social groups, political groups, religious groups, professional associations, racial groups, nations - ensuring dysfunctional behaviors. Approximately 250 students have taken this elective course in the past eight years. Even if $10 \%$ have implemented this additional paradigm of leadership as a personal journey into day-to-day decision making, the author's original idea of young men and women who are aware of their own influences and assumptions in leadership positions will begin to snowball.

\section{Acknowledgements}

The author acknowledges Indian Institute of Management Udaipur (IIMU) in India for enabling this initiative in Leadership Coaching which started in 2013. The course is offered in the final year of a 02-year full-time, residential MBA programme. Average age of the Class has been 23. The course is spread over four months, in 34 ninety-minute sessions, and covers traditional leadership training blended with psycho-dynamic theories and Freudian counselling sessions with each student,

The version in 2020 was held on-line because of the pandemic. 
Founded in 2011, IIMU is AACSB-accredited and ranks 5th. amongst top b-schools in India (www.iimudaipur.ac.in).

\section{References}

[1] Jugaad: A New Growth Formula for Corporate America. Harvard Business Review Blog Network. 25 Jan 2010.

[2] India's Next Global Export: Innovation. Bloomberg Business Week. 02 Dec 2009.

[3] Prabhu, Jaideep. (2013). Retrieved 12 July 21 from http://www.hindustantimes.com/india/cambridge-expert-saysindian-jugaad-is-lesson-to-world/storyM3q6vFu8tEPj8eSNsAJo5M.html).

[4] Dutta, Soumitra and Escalona Reynoso, Rafael. SC Johnson College of Business, Cornell University et al. (2020). Retrieved 12 July 21 from Chapter 1, Page 19 of www.globalinnovationindex.org.

[5] Tharoor, S. Press Trust of India. Updated 25 October 2018.

[6] Kets de Vries, M. Conversations on Leadership: Wisdom from Global Management Gurus. Liu, Lan. Jossey-Bass. 2010.

[7] Drucker, Peter F. Management: Tasks, Responsibilities, Practices. Harper Collins. 1993.

[8] Garg, Pulin. Cultural Identities: Their Implications for Patterns of Leadership in Indian Organisations. https://sumedhas.org.in/index.php/paper-publications/paperspublications. 1987.
[9] Mitchell, Stephen and Black, Margaret. Freud and Beyond. Basic Books, Perseus Books Group, NY, USA. 1995.

[10] Brown, Brene. Secrets for Healing Yourself and Making an Impact in the World. Lewishowes.com/podcast

[11] Capelli, P et al. Leadership Lessons from India. HBR, March 2010.

[12] Retrieved $10 \quad$ June 21 from https://globeproject.com/results/countries/IND\#country.

[13] Kakar, S. The Indians: Portrait of a People. Penguin India. 2009.

[14] Chattopadhyay, GP. Managing Oneself in Role in the Indian Context. Journal of Indian Anthropological Society. October 2004.

[15] Bion, WR. Elements of Psychoanalysis. Heinemann, London. 1963.

[16] What is a Group Relations Conference? Announcement of Leicester Conference 2021 in www.tavinstitute.org.

[17] Neuroplastcity. Nervous System Physiology. NCLEX-RN. (2014) Khan Academy.

[18] Kolb, David A. Experiential learning: Experience as the source of learning and development (Vol. 1). Englewood Cliffs, NJ, Prentice-Hall. 1984.

[19] Kets de Vries, M. HBR. April 2014. 